\title{
IN VITRO ROOTING OF NEPENTHES TRUNCATA MACF.
}

Eufemio T. Rasco, Jr. • Georgianna Kae R. Oguis • Cyrose Suzie C. Silvosa • College of Science and Mathematics $\bullet$ University of the Philippines Mindanao $\bullet$ Mintal $\bullet$ Davao City $\bullet$ Philippines •g.kae.oguis@gmail.com

Keywords: in vitro rooting, Nepenthes truncata, IBA.

Rooting is an important stage in propagation of in vitro-grown delicate plants such as Nepenthes truncata. With well-developed root systems, plants are hardy enough to withstand changes in the environment during transfer from laboratory to nursery, thereby ensuring high survival rates.

In order to establish well-developed roots of $N$. truncata cuttings, we designed a series of experiments to explore a more suitable alternative to agar-based media and determine the appropriate plant growth regulator (PGR), PGR concentration, and method of application. Root length, root color, shoot length, shoot color, and survival rates were assessed. Statistical analyses were done using ANOVA $(\alpha=0.05$, CropStat ver. 7.2.3). All culture media used full Murashige and Skoog media adjusted to $5.75 \pm 0.05 \mathrm{pH}$ prior to sterilization; plantlet cultures were kept under $25 \pm 2^{\circ} \mathrm{C}$, with light intensity of 3000 lux.

\section{Effect of Plantlet Size and PGR on In Vitro Root Development}

To determine the effect of plantlet size and PGR on root development of in vitro Nepenthes truncata, small $(<1 \mathrm{~cm}$ height, leaf width $\leq 2 \mathrm{~mm}$ ) and medium (between $1 \mathrm{~cm}$ to $3 \mathrm{~cm}$ height, leaf width $>2 \mathrm{~mm})$. Clone 4 plantlets were grown in $(0.6 \% \mathrm{w} / \mathrm{v})$ agar media supplemented with different Plant Growth Regulator (PGR) concentrations: $1 \mathrm{~mL} \cdot \mathrm{L}^{-1}$ Hormex ${ }^{\circledR}, 3 \mathrm{~mL} \cdot \mathrm{L}^{-1}$ Hormex ${ }^{\circledR}$, $1 \mathrm{mg} \cdot \mathrm{L}^{-1} \quad \mathrm{IBA}$ and $3 \mathrm{mg} \cdot \mathrm{L}^{-1}$ IBA. Plantlet survival and rooting parameters were noted for 4 months. It was a completely randomized $2 \times 4$ factorial experiment consisting of 8 replicates with 5 plantlets per replicate.

Rooting parameters and plantlet survival were significantly affected by the PGRs used and these were constantly highest in plantlets supplemented with $3 \mathrm{mg} \cdot \mathrm{L}^{-1}$ IBA. Plantlets supplemented with Hormex ${ }^{\circledR}$, a commercially-available PGR containing vitamin B1, NAA, and IBA, produced callus while those supplemented solely with IBA grew root hairs (Fig. 1). Callus production impeded plantlet survival as callus creates an incomplete and weak connection between roots and shoots. In contrast, the presence of root hairs in plantlets supplemented with IBA aided in water absorption and translocation (Dhillon et al. 2011).

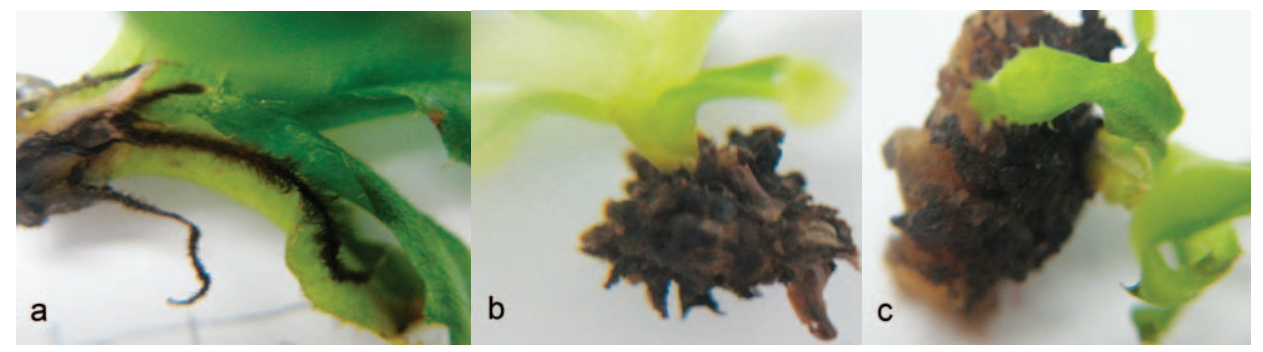

Figure 1: Roots in medium plantlets supplemented with and $3 \mathrm{mg} \cdot \mathrm{L}^{-1}$ Indole-3-butyricacid (a), $1 \mathrm{~mL} \cdot \mathrm{L}^{-1} \operatorname{Hormex} \circledast(\mathrm{b})$, and $3 \mathrm{~mL} \cdot \mathrm{L}^{-1} \operatorname{Hormex} \circledast(\mathrm{c})$. 
Table 1. Mean \pm s.e. root count, root length rating, root color rating, and number of survivors of Nepenthes truncata clones under different rooting treatments for three months.

Note: Each value is the mean of 8 replicates with 5 plantlets per replicate. Values were $\operatorname{sqrt}(x+0.5)$ transformed prior to analysis.

\begin{tabular}{|c|c|c|c|c|}
\hline Treatments & Root count & Root length & Root color & Survivor \\
\hline \multicolumn{5}{|c|}{ Size } \\
\hline Small & $1.03 \pm 0.42$ & $0.92 \pm 0.35$ & $0.89 \pm 0.24$ & $1.72 \pm 0.70$ \\
\hline Medium & $1.06 \pm 0.63$ & $1.02 \pm 0.42$ & $0.93 \pm 0.38$ & $2.00 \pm 0.67$ \\
\hline \multicolumn{5}{|c|}{ PGR } \\
\hline Control $(\mathrm{Co})$ & $0.88 \pm 0.10$ & $0.85 \pm 0.15$ & $0.80 \pm 0.04$ & $1.85 \pm 0.79$ \\
\hline $1 \mathrm{~mL} \cdot \mathrm{L}^{-1} \operatorname{Hormex}^{\circledR}(\mathrm{P} 1)$ & $0.13 \pm 0.24$ & $0.99 \pm 0.21$ & $0.96 \pm 0.24$ & $1.72 \pm 0.67$ \\
\hline $3 \mathrm{~mL} \cdot \mathrm{L}^{-1} \operatorname{Hormex}^{\circledR}(\mathrm{P} 2)$ & $0.74 \pm 0.80$ & $0.76 \pm 0.53$ & $0.72 \pm 0.41$ & $1.63 \pm 0.13$ \\
\hline $1 \mathrm{mg} \cdot \mathrm{L}^{-1} \mathrm{IBA}(\mathrm{P} 3)$ & $0.79 \pm 0.43$ & $0.78 \pm 0.36$ & $0.78 \pm 0.25$ & $1.81 \pm 0.72$ \\
\hline $3 \mathrm{mg} \cdot \mathrm{L}^{-1} \mathrm{IBA}(\mathrm{P} 4)$ & $1.67 \pm 0.58$ & $1.46 \pm 0.41$ & $1.28 \pm 0.37$ & $2.29 \pm 0.68$ \\
\hline \multicolumn{5}{|c|}{ Size $\times$ PGR } \\
\hline \multicolumn{5}{|c|}{ Small } \\
\hline $\mathrm{Co}$ & $0.71 \pm 0.00$ & $0.71 \pm 0.00$ & $0.71 \pm 0.00$ & $1.58 \pm 0.27$ \\
\hline $\mathrm{P} 1$ & $1.28 \pm 0.38$ & $1.06 \pm 0.20$ & $1.04 \pm 0.16$ & $1.62 \pm 0.07$ \\
\hline $\mathrm{P} 2$ & $0.71 \pm 0.19$ & $0.71 \pm 0.13$ & $0.71 \pm 0.08$ & $1.47 \pm 0.22$ \\
\hline P3 & $0.71 \pm 0.21$ & $0.71 \pm 0.15$ & $0.71 \pm 0.12$ & $1.70 \pm 0.26$ \\
\hline $\mathrm{P} 4$ & $1.73 \pm 0.03$ & $1.45 \pm 0.06$ & $1.27 \pm 0.02$ & $2.23 \pm 0.28$ \\
\hline \multicolumn{5}{|c|}{ Medium } \\
\hline $\mathrm{Co}$ & $1.06 \pm 0.06$ & $0.10 \pm 0.06$ & $0.90 \pm 0.03$ & $2.11 \pm 0.23$ \\
\hline $\mathrm{P} 1$ & $0.97 \pm 0.22$ & $0.93 \pm 0.20$ & $0.87 \pm 0.13$ & $1.82 \pm 0.00$ \\
\hline $\mathrm{P} 2$ & $0.78 \pm 0.00$ & $0.82 \pm 0.00$ & $0.74 \pm 0.00$ & $1.80 \pm 0.27$ \\
\hline P3 & $0.87 \pm 0.13$ & $0.85 \pm 0.08$ & $0.86 \pm 0.08$ & $1.92 \pm 0.24$ \\
\hline $\mathrm{P} 4$ & $1.61 \pm 0.00$ & $1.51 \pm 0.00$ & $1.29 \pm 0.00$ & $2.35 \pm 0.30$ \\
\hline \multicolumn{5}{|c|}{ P-Values } \\
\hline Size & 0.76 & 0.16 & 0.44 & 0.04 \\
\hline PGR & 0.00 & 0.00 & 0.00 & 0.03 \\
\hline Size $\times$ PGR & 0.02 & 0.00 & 0.00 & 0.04 \\
\hline
\end{tabular}

Although plantlet size did not significantly affect root count, root length, and root color (Table 1), survival was significantly higher $(\mathrm{p}=0.04)$ in medium plantlets. In addition, unlike medium plantlets, small plantlets grown in PGR-free media did not root.

Effect of Rooting Media on Root and Shoot Development and Survival of In Vitro Plantlets

Five pooled clone lines (Clones 3, 4, 7, 11, and 18) under a unifactorial completely randomized experiment were used to determine the effect of rooting media on root development of in vitro $N$. truncata plantlets. Pooled clone lines comprised 23 replicates with 5 plantlets per replicate. Replicates 1 to 6,7 to 10,11 to 17,18 to 20, and 21 to 23 were assigned to Clones 4 , $3,11,7$, and 18, respectively. Medium-sized (1 to $3 \mathrm{~cm}$ ) plantlets were transferred to: (1) $10 \mathrm{~mL}$ $(0.6 \% \mathrm{w} / \mathrm{v})$ agar media and $10 \mathrm{~g}$ of (2) vermiculite and (3) Silvosa medium (2:1:1 ratio of coco coir:osmunda fiber:charcoaled rice hull). PGR and activated charcoal were not incorporated in the media. Plantlet survival, shooting, and rooting parameters were noted for 3 months. 
Table 2. Mean \pm s.e. number of survivors, shoot count, shoot length, shoot color, root count, root length, and root color and P-values of Nepenthes truncata grown in different media for 3 months.

Note: Each value is the mean of 23 replicates with 5 plantlets per replicate. Values were sqrt $(x+0.5)$ transformed prior to analysis.

\begin{tabular}{|c|c|c|c|c|c|}
\hline \multirow{2}{*}{ Survivors } & Agar & Vermiculite & Silvosa & P-value & LSD $(0.05)$ \\
\cline { 2 - 6 } & $1.27 \pm 0.45$ & $1.85 \pm 0.51$ & $1.21 \pm 0.64$ & 0.00 & 0.30 \\
\hline \multicolumn{7}{|c|}{ Shoot } \\
\hline Count & $2.96 \pm 1.76$ & $1.90 \pm 0.56$ & $1.20 \pm 0.64$ & 0.00 & 0.68 \\
\hline Length & $1.37 \pm 0.36$ & $1.43 \pm 0.16$ & $1.42 \pm 0.30$ & 0.58 & 0.13 \\
\hline Color & $1.44 \pm 0.39$ & $1.57 \pm 0.00$ & $1.54 \pm 0.28$ & 1.21 & 0.13 \\
\hline \multicolumn{7}{|c|}{ Root } \\
\hline Count & $0.79 \pm 0.38$ & $1.07 \pm 0.24$ & $0.84 \pm 0.33$ & 0.01 & 0.17 \\
\hline Length & $1.54 \pm 0.00$ & $1.57 \pm 0.28$ & $1.50 \pm 0.18$ & 0.21 & 0.08 \\
\hline Color & $1.44 \pm 0.00$ & $1.47 \pm 0.26$ & $1.40 \pm 0.00$ & 0.24 & 0.08 \\
\hline
\end{tabular}

Vermiculite was apparently the best rooting medium as it significantly produced the greatest number of survivors and the most roots (Table 2). Root length was also highest in vermiculite. In a study comparing plantlet rooting in vermiculite and gerlite (a solid medium), vermiculite promoted rooting better and it promoted penetration and aeration of the roots more than the latter (Jay-Allemand et al. 1992).

Shoot count was significantly highest among plantlets grown in agar. Shoot production was ten times faster in agar than in vermiculite and Silvosa medium (Figs. 2 \& 3).

Because vermiculite is only good for rooting and agar for shoot formation, it would be better to grow plantlets in agar until they produced ample number of shoots prior to transfer in vermiculite. Transferring previously rooted plantlets to agar might degrade root quality since nutrient reserves of plantlets will then be utilized for shoot production.

Effect of Cutting Source and IBA Concentration on Root and Shoot Development of In Vitro Plantlets

The effect of 3 IBA concentrations ( $3 \mathrm{mg} \cdot \mathrm{L}^{-1} \mathrm{IBA}, 6 \mathrm{mg} \cdot \mathrm{L}^{-1} \mathrm{IBA}$, and $9 \mathrm{mg} \cdot \mathrm{L}^{-1} \mathrm{IBA}$ ) on root development of tip and base in vitro plantlets was also tested in Clone 4 where 8 replicates with 5 plantlets per replicate were used. It was a completely randomized $3 \times 2$ factorial experiment. Plantlets were irrigated with $18 \mathrm{~mL}$ full-strength MS and grown in $10 \mathrm{~g}$ vermiculite. Shooting and rooting parameters were observed for 4 months.

Root and shoot parameters were not significantly different between plantlets from different cutting locations (tip and base) supplemented with different IBA concentrations (Table 3). The root and shoot parameters were not significantly affected by the application of 3 different IBA concentrations. Loca-

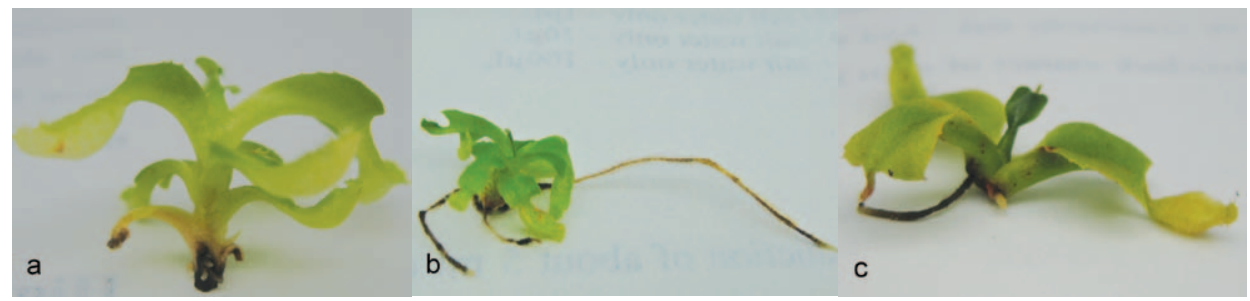

Figure 2: Nepenthes truncata plantlets placed in agar (a), vermiculite (b), and Silvosa medium (c) for 4 months. 


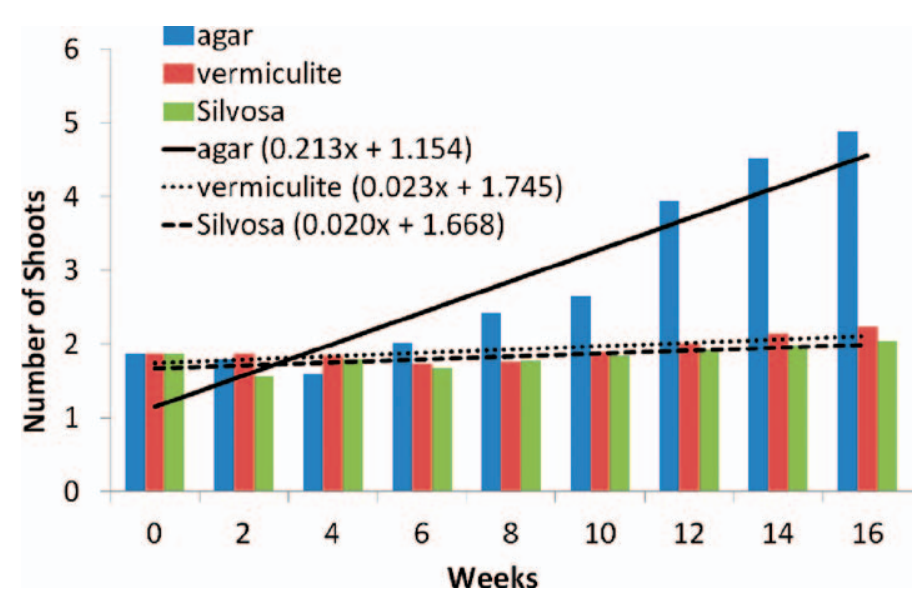

Figure 3: Shoot count of plantlets grown in different rooting media for 4 months.

tion of plantlet cuttings also did not influence root and shoot development. In the 2 cutting locations, the supplemented auxin was likely equally absorbed, and there was also no disparity in mineral composition (Schwambach et al. 2005).

Effect of IBA Application on Root and Shoot Development of In Vitro Plantlets

Two methods of IBA application were also compared in Clone 18: (a) incorporating IBA in 10 $\mathrm{g}$ vermiculite and (b) dipping cuttings for 10 minutes in IBA ranging from $10 \mathrm{mg} \cdot \mathrm{L}^{-1}$ to $100 \mathrm{mg} \cdot \mathrm{L}^{-1}$ prior to transferring in IBA-free $10 \mathrm{~g}$ vermiculite (Table 4). It was a completely randomized unifactorial experiment consisting of 4 replicates with 5 explants per replicate. Shooting and rooting parameters were observed for one month.

Although in most cases, shoot and root development of plantlets dipped for 10 minutes in differ-

Table 3. Mean \pm s.e. number of survivors, shoot count, shoot length, shoot color, root count, root length, and root color of tip and base and P-values of Nepenthes truncata plantlets supplemented with different indole-3-butyric acid (IBA) concentrations for 3 months.

Note: Each value is the mean of 8 replicates with 5 plantlets per replicate. Values were $\operatorname{sqrt}(x+0.5)$ transformed prior to analysis.

\begin{tabular}{|c|c|c|c|c|c|c|c|}
\hline \multirow[b]{2}{*}{ Location } & \multirow{2}{*}{$\begin{array}{c}\text { IBA } \\
\text { concentration } \\
\left.(\text { Conc. }) \mathrm{mg} \cdot \mathrm{L}^{-1}\right)\end{array}$} & \multicolumn{3}{|c|}{ Shoot } & \multicolumn{3}{|c|}{ Root } \\
\hline & & Count & Length & Color & Count & Length & Color \\
\hline \multirow{3}{*}{ Tip } & 3 & $2.04 \pm 0.21$ & $1.67 \pm 0.10$ & $1.59 \pm 0.022$ & $1.93 \pm 0.52$ & $1.56 \pm 0.29$ & $1.51 \pm 0.24$ \\
\hline & 6 & $1.95 \pm 0.16$ & $1.65 \pm 0.05$ & $1.59 \pm 0.047$ & $2.02 \pm 0.75$ & $1.65 \pm 0.38$ & $1.46 \pm 0.43$ \\
\hline & 9 & $2.00 \pm 0.16$ & $1.60 \pm 0.10$ & $1.56 \pm 0.02$ & $1.67 \pm 0.70$ & $1.31 \pm 0.37$ & $1.25 \pm 0.42$ \\
\hline \multirow{3}{*}{ Base } & 3 & $1.94 \pm 0.13$ & $1.65 \pm 0.10$ & $1.58 \pm 0.02$ & $1.81 \pm 0.57$ & $1.56 \pm 0.31$ & $1.51 \pm 0.25$ \\
\hline & 6 & $1.89 \pm 0.11$ & $1.66 \pm 0.06$ & $1.59 \pm 0.00$ & $1.91 \pm 0.40$ & $1.56 \pm 0.27$ & $1.46 \pm 0.22$ \\
\hline & 9 & $1.95 \pm 0.18$ & $1.61 \pm 0.06$ & $1.58 \pm 0.00$ & $2.00 \pm 0.84$ & $1.66 \pm 0.31$ & $1.34 \pm 0.32$ \\
\hline \multirow{3}{*}{$\mathrm{P}$-value } & Conc. & 0.40 & 0.50 & 0.14 & 0.53 & 0.19 & 0.55 \\
\hline & Location & 0.56 & 0.78 & 0.06 & 0.59 & 0.07 & 0.73 \\
\hline & Conc. $\times$ Loc. & 0.37 & 0.27 & 0.34 & 0.99 & 0.74 & 0.16 \\
\hline
\end{tabular}


Table 4. Mean \pm s.e. root count, root length, root color, shoot count, shoot length, and shoot color of Nepenthes truncata plantlets dipped at different IBA concentrations for 10 minutes and grown in IBA-free media for one month.

Note: Each value is the mean of 4 replicates with 5 plantlets per replicate. Values were $\operatorname{sqrt}(x+0.5)$ transformed prior to analysis. $\mathrm{IM}=$ incorporated in the media.

\begin{tabular}{|c|c|c|c|c|c|c|}
\hline \multirow{2}{*}{$\begin{array}{c}\text { IBA } \\
\begin{array}{c}\text { IBncentration } \\
\left(\mathrm{mg} \cdot \mathrm{L}^{-1}\right)\end{array}\end{array}$} & Count & Length & Color & Count & Length & Color \\
\cline { 2 - 7 } & $1.87 \pm 0.09$ & $1.64 \pm 0.04$ & $1.58 \pm 0.00$ & $1.02 \pm 0.22$ & $0.85 \pm 0.09$ & $0.90 \pm 0.14$ \\
\hline $3(\mathrm{IM})$ & $1.75 \pm 0.06$ & $1.63 \pm 0.03$ & $1.54 \pm 0.04$ & $0.97 \pm 0.13$ & $0.95 \pm 0.11$ & $0.92 \pm 0.10$ \\
\hline 10 & $1.90 \pm 0.09$ & $1.76 \pm 0.13$ & $1.58 \pm 0.00$ & $1.11 \pm 0.20$ & $0.96 \pm 0.12$ & $0.92 \pm 0.10$ \\
\hline 20 & $1.86 \pm 0.14$ & $1.59 \pm 0.06$ & $1.53 \pm 0.07$ & $0.93 \pm 0.14$ & $0.86 \pm 0.13$ & $0.81 \pm 0.07$ \\
\hline 30 & $1.86 \pm 0.13$ & $1.61 \pm 0.03$ & $1.58 \pm 0.03$ & $1.63 \pm 0.34$ & $1.33 \pm 0.21$ & $1.21 \pm 0.18$ \\
\hline 40 & $1.85 \pm 0.04$ & $1.67 \pm 0.07$ & $1.62 \pm 0.09$ & $0.84 \pm 0.14$ & $0.81 \pm 0.10$ & $0.80 \pm 0.09$ \\
\hline 50 & $1.90 \pm 0.09$ & $1.68 \pm 0.06$ & $1.51 \pm 0.05$ & $1.07 \pm 0.19$ & $0.86 \pm 0.07$ & $0.86 \pm 0.07$ \\
\hline 60 & $1.75 \pm 0.10$ & $1.59 \pm 0.05$ & $1.52 \pm 0.04$ & $0.91 \pm 0.21$ & $0.79 \pm 0.08$ & $0.79 \pm 0.08$ \\
\hline 70 & $1.80 \pm 0.04$ & $1.64 \pm 0.04$ & $1.56 \pm 0.02$ & $0.99 \pm 0.21$ & $0.83 \pm 0.08$ & $0.81 \pm 0.07$ \\
\hline 80 & $1.86 \pm 0.04$ & $1.71 \pm 0.05$ & $1.52 \pm 0.05$ & $1.11 \pm 0.22$ & $0.96 \pm 0.17$ & $0.91 \pm 0.11$ \\
\hline 90 & $1.80 \pm 0.08$ & $1.65 \pm 0.11$ & $1.47 \pm 0.07$ & $0.93 \pm 0.23$ & $0.82 \pm 0.11$ & $0.85 \pm 0.15$ \\
\hline 100 & 0.583 & 0.676 & 0.727 & 0.237 & 0.089 & 0.223 \\
\hline p-value & 0.179 & 0.162 & 0.139 & 0.513 & 0.318 & 0.292 \\
\hline LSD $(0.05)$ & & & & &
\end{tabular}

ent IBA concentrations were similar to plantlets grown in media supplemented with $3 \mathrm{mg} \cdot \mathrm{L}^{-1} \mathrm{IBA}$, the latter is time-efficient and less laborious.

\section{Conclusions}

Our study shows that vermiculite can be used as a more suitable alternative to agar-based media for rooting in vitro grown Nepenthes truncata. Plantlet size, cutting location, and method of application did not significantly affect in vitro rooting. Dipping cuttings for 10 minutes in IBA concentrations ranging from $10 \mathrm{mg} \cdot \mathrm{L}^{-1}$ to $100 \mathrm{mg} \cdot \mathrm{L}^{-1}$ before transferring in an IBA-free medium is just as efficient as incorporating $3 \mathrm{mg} \cdot \mathrm{L}^{-1} \mathrm{IBA}$ in the medium.

\section{References}

Dhillon, R.S., Hooda, M.S., Pundeer, J.S., Ahlawat, K.S., and Chopra, I. 2011. Effects of auxins and thiamine on the efficacy of techniques of clonal propagation in Jatropha curcas L. Biomass and Bioenergy 35(4): 1502-1510.

Jay-Allemand, C., Capelli, P., and Cornu, D. 1992. Root development of in vitro hybrid walnut microcuttings in a vermiculite-containing gelrite medium. Scientia Horticulturae 51(3-4): 335-342.

Ofori, D.A., Newton, A.C., Leakey, R.R.B., and Grace, J. 1996. Vegetative propagation of Milicia excelsa by leafy stem cuttings: effects of auxin concentration, leaf area and rooting medium. Forest Ecology and Management 84(1-3): 39-48.

Schwambach, J., Fadanelli, C., and Fett-Neto, A.G. 2005. Mineral nutrition and adventitious rooting in microcuttings of Eucalyptus globulus. Tree Physiol 25(4): 487-494. 